\title{
Most commonly isolated viruses in asthma exacerbation and their correlation with eosinophil and total serum immunoglobulin E levels
}

\author{
Mireya Robledo Aceves. Doctor of Science ${ }^{a}$. Alejandro Barrón Balderas. M.D. ${ }^{a}$ and \\ María de L. Jaime Ornelas. M.D. ${ }^{b}$
}

\begin{abstract}
Background. Asthma exacerbations are still a cause of hospitalization at the Emergency Department. Thetriggers of asthma exacerbations include allergens and infections -mostly viral-. The objective of this study was to establish the relationship between viruses detected during an asthma exacerbation and eosinophil and serum immunoglobulin E (IgE) levels in pediatric patients.

Population and methods. Cross-sectional. analytical study. Children aged 5-15 years seen at the Pediatric Emergency Department with an asthma exacerbation in the period between March 2013 and February 2016 were included. Viral ribonucleic acid was extracted from nasopharyngeal aspirates using the CLART Pneumo Vir kit. Eosinophil levels were measured in peripheral blood and total IgE levels, in serum. Eosinophilia was defined as a count $\geq 0.4 \times 103$ / $\mathrm{mm}^{3}$ and high IgE. as a level $\geq 350 \mathrm{IU} / \mathrm{L}$. The Pearson's correlation was carried out. A value of $\mathrm{p} \leq 0.05$ was considered significant.

Results. Out of 211 children with asthma exacerbation, a virus was isolated in $20 \%$. The most commonly isolated viruses were rhinovirus. enterovirus, and respiratory syncytial virus. A correlation of 0.89 was established between eosinophil and total serum IgE levels in children with asthma exacerbation and rhinovirus, with a $p$ value of 0.0001 .

Conclusions. Rhinovirus, enterovirus, and respiratory syncytial virus were the most common viruses in asthma exacerbations in children younger than 15 years. A correlation was established between eosinophil and $\operatorname{IgE}$ levels in the presence of rhinovirus.

Key words: rhinovirus, asthma, eosinophils, immunoglobulin E.
\end{abstract}

http:/ / dx.doi.org/10.5546/ aap.2018.eng.192

To cite: Robledo Aceves M. Barrón Balderas A. Jaime Ornelas ML. Most commonly isolated viruses in asthma exacerbation and their correlation with eosinophil and total serum immunoglobulin E levels. Arch Argent Pediatr 2018;116(3):192-197.

\section{INTRODUCTION}

Asthma exacerbations are still one of the main causes of hospitalization in the Emergency Department. They are triggered by allergen sensitization, infections, and genetic factors. ${ }^{1,2}$ Viral infections are one of the agents involved in an already allergensensitized inflammatory process; some authors suggest that recurrent infections during early childhood are the cause of such frequent exacerbations, together with poorlycontrolled asthma and the resulting hospitalizations. ${ }^{3,4}$

Rhinovirus is the most commonly isolated virus in people who develop asthma exacerbations, both children and adults. ${ }^{5-7}$ Most children with asthma have atopy. ${ }^{8}$ Gaining understanding of the relationship between specific viral infections and allergic sensitization in asthmatic children will probably help to create strategies aimed at preventing exacerbations.

The objective of this study was to establish the relationship between viruses detected during an asthma exacerbation and eosinophil and serum immunoglobulin E ( $\mathrm{IgE}$ ) levels in pediatric patients.

\section{POPULATION AND METHODS}

The study was conducted at the Pediatric Emergency Department of Hospital Civil de Guadalajara Dr. Juan I. Menchaca, Jalisco, Mexico. This was a cross-sectional, analytical study. The study population was made up of children hospitalized due to an asthma exacerbation between March 2013 and February 2016. The study group consisted of children with asthma exacerbation aged 5-15 years. 
An asthma exacerbation was diagnosed based on the clinical presentation of sudden wheezing, cough, dyspnea, polypnea, accessory muscle use, radiographic findings of air trapping, history of prior wheezing in more than two occasions in 1 year, and nocturnal symptoms. ${ }^{1,9}$ All children who met the criteria for asthma exacerbation had a viral panel; those with asthma exacerbation who had pneumonia or suspected bacterial infection were excluded from the panel. Only children with asthma exacerbation and a positive viral panel had their eosinophil level measured in peripheral blood and total IgE measured in serum. Blood eosinophils were measured using a flow cytometry. Eosinophilia was defined as an eosinophil level $>0.4 \times 103 / \mathrm{mm}^{3}$. Total serum IgE levels were measured using an immunoassay, IgE was considered high if it was > $350 \mathrm{IU} / \mathrm{L}$. Inclusion criteria: All children with asthma exacerbations who attended the Emergency Department for the first time were assessed and those with a positive panel for one or more viruses were included.

\section{Virus detection}

Virus samples were collected from the nasopharynx through the nostril by inserting a disposable suction catheter connected to an extractor. Viral ribonucleic acid (RNA) was extracted from the nasopharyngeal aspirate using the CLART PneumoVir kit by amplification of specific fragments from the virus genome and using a specific probe hybridization for each virus. Detected viruses included adenovirus, metapneumovirus A and B, parainfluenza 1, 2, 3, and 4, respiratory syncytial virus (RSV) A and B, bocavirus, coronavirus, H1N1 influenza, H3N2 influenza, influenza $B$ and $C$, rhinovirus, and enterovirus.

\section{Statistics}

For the statistical analysis, quantitative outcome measures were described as mean \pm standard deviation and range. Qualitative outcome measures were expressed as percentage. The Pearson's correlation was used to measure the correlation between eosinophil and total IgE levels in serum. A value of $p<0.05$ was considered significant. This study was approved by the Ethics and Research Committee of Hospital Civil de Guadalajara; parents' written consent was obtained. The IBM SPSS Statistics software, version 21, and Microsoft Excel, version 14.4.5. were used.

\section{RESULTS}

\section{Sample characteristics}

Out of 211 children with asthma exacerbation, 120 were boys (56.9\%) and $43.1 \%$, girls, and their average age was 97.8 months (range: $60-180$ months). Ninety-seven children were hospitalized between September and November $(46 \%)$ and 42 $(20 \%)$ had a positive viral panel with isolation of one or more viruses (Table 1).

\section{Isolated viruses}

Rhinovirus was the most commonly isolated virus, in $26.9 \%$ (14 cases), followed by enterovirus, in $19.2 \%$ (10 cases), RSV type B was isolated in 9.6\% (5 cases); RSV type A and bocavirus, in $7.6 \%$ (4 cases); parainfluenza 3, adenovirus, and $\mathrm{H} 3 \mathrm{~N} 2$ influenza, in $5.7 \%$ (3 cases); influenza type $B$, metapneumovirus $B$, and parainfluenza 1 , in $4 \%$ (1 case). Two viruses were isolated in the viral panel of 10 children with asthma exacerbation (23.8\%). Rhinovirus was the most common virus found in association with another virus: 2 cases also had RSV A, and 1 case each also had RSV B, enterovirus, parainfluenza 3, parainfluenza 1 , and metapneumovirus, H3N2 influenza and RSV B were isolated in 1 case; influenza $B$ and bocavirus, in 1 case; and RSV A and B, in 1 case (Table 2).

Children with a positive viral panel were stratified into asthma exacerbation caused by rhinovirus, asthma exacerbation caused by enterovirus, and asthma exacerbation caused by other virus (Table 3). The average age of children in the three groups was similar, between 84 and 113 months. A mild prevalence of male sex was observed among children with asthma exacerbations and isolated viruses, but it was not statistically significant. In the rhinovirus group, $57.1 \%$ were boys; in the enterovirus group, $88.9 \%$; and in the other virus group, $63.2 \%$.

TABLE 1. Characteristics of children with asthma exacerbation

\begin{tabular}{lc}
\hline Characteristic & $\mathbf{n}=\mathbf{2 1 1}$ \\
\hline Age (months) (average \pm SD [range]) & $97.8 \pm 41.3(60-180)$ \\
Sex (female/male [\%]) & $91 / 120(43.1 / 56.9)$ \\
Season (n/\%) & $38(18)$ \\
March through May (spring) & $34(16)$ \\
June through August (summer) & $97(46)$ \\
September through November (fall) & $42(20)$ \\
December through February (winter) & $42(20)$ \\
Positive viral panel (n/\%) & \\
\hline
\end{tabular}

SD: standard deviation. 


\section{Eosinophil and total serum immunoglobulin E levels}

The investigation of the medical history of children with asthma exacerbation and an isolated virus included allergic rhinitis, atopic dermatitis, and a family history of asthma or allergies. The incidence of atopy was not higher in children with asthma exacerbation and an isolated virus. In relation to serum eosinophil levels in children with asthma exacerbation and an isolated virus, it was observed that the average eosinophil level was $0.31 \times 10^{3} / \mathrm{mm}^{3}$ in the rhinovirus group, $0.18 \times 10^{3} / \mathrm{mm}^{3}$ in the enterovirus group, and

TABLE 2. Isolated respiratory viruses

\begin{tabular}{lcc}
\hline Virus & $\%$ & Number \\
\hline Rhinovirus & 26.9 & 14 \\
Enterovirus & 19.2 & 10 \\
Respiratory syncytial virus B & 9.6 & 5 \\
Respiratory syncytial virus A & 7.6 & 4 \\
Bocavirus & 7.6 & 4 \\
Parainfluenza 3 & 5.7 & 3 \\
Adenovirus & 5.7 & 3 \\
H3N2 influenza & 5.7 & 3 \\
Influenza B & 4 & 2 \\
Metapneumovirus B & 4 & 2 \\
Parainfluenza 1 & 4 & 2 \\
Total & 100 & 52 \\
Co-infection with two viruses & & \\
$\quad$ Rhinovirus + RSV A & 20 & 2 \\
$\quad$ Rhinovirus + RSV B & 10 & 1 \\
$\quad$ Rhinovirus + enterovirus & 10 & 1 \\
$\quad$ Rhinovirus + parainfluenza 3 & 10 & 1 \\
$\quad$ Rhinovirus + parainfluenza 1 & 10 & 1 \\
$\quad$ H3N2 influenza A + RSV B & 10 & 1 \\
$\quad$ Influenza B + bocavirus & 10 & 1 \\
$\quad$ RSV A + RSV B & 10 & 1 \\
Total & 100 & 10 \\
\hline RSV: respiratory syncytial virus. & & \\
\hline
\end{tabular}

RSV: respiratory syncytial virus.
$0.01 \times 10^{3} / \mathrm{mm}^{3}$ in the other virus group. Although none of the 3 groups showed a prevalence of eosinophilia, the cases with rhinovirus isolation had higher blood eosinophil levels compared to the other 2 groups. Total IgE levels in serum were measured in children with asthma exacerbation and an isolated virus; the average total serum IgE level was $299 \mathrm{U} / \mathrm{L}$ in the rhinovirus group; $271 \mathrm{U} / \mathrm{L}$ in the enterovirus group; and $679.9 \mathrm{U} / \mathrm{L}$ in the other virus group, Although total serum IgE levels in children with asthma exacerbation and an isolated virus were higher, when a correlation was established between serum eosinophil and total serum IgE levels in the 3 groups, a positive correlation was observed in the rhinovirus group, which was 0.89 with a $\mathrm{p}=0.0001$, and in the enterovirus group, which was 0.81 with a $p=0.01$ (Figure 1).

\section{DISCUSSION}

The prevalence of asthma varies from one region to another. The International Study of Asthma and Allergies in Childhood (ISAAC) has reported differences in the asthma prevalence between $20 \%$ and $60 \%$ among schoolchildren worldwide. In Mexico, the prevalence of asthma ranges between $2.7 \%$ and $21.8 \%{ }^{10}$ In our study we found that the accumulated prevalence of asthma exacerbation was $2.15 \%$. Approximately $1-2 \%$ of children with asthma require hospitalization due to respiratory distress. ${ }^{11}$

Asthma exacerbation occurred more commonly $(46 \%)$ in fall, which corresponded to the September-November quarter, and less frequently in summer, which corresponded to the June-August quarter, with $16 \%$ of admissions to the Emergency Department. It was different from what was reported by Barraza et al. and Vázquez et al. who observed that the greatest prevalence

TABLE 3. Clinical characteristics according to the isolated virus

\begin{tabular}{|c|c|c|c|}
\hline Characteristics & Rhinovirus ( $n=14$ ) & Enterovirus $(n=9)$ & Other virus $(n=19)$ \\
\hline Age (months) & $96.6 \pm 28.8$ & $94.44 \pm 30$ & $113.2 \pm 40.8$ \\
\hline Male sex $(\%)$ & $8(57.1)$ & $8(88.9)$ & $12(63.2)$ \\
\hline \multicolumn{4}{|l|}{ History } \\
\hline Allergic rhinitis & $4(28.6)$ & $6(66.7)$ & $10(52.6)$ \\
\hline Atopic dermatitis & $2(14.3)$ & $4(44.4)$ & $6(31.6)$ \\
\hline History of atopy & $8(57.1)$ & $7(77.8)$ & $9(47.4)$ \\
\hline Eosinophils $\left(\times 10^{3} / \mathrm{mm}^{3}\right)$ & $0.31 \pm 0.34$ & $0.18 \pm 0.22$ & $0.01 \pm 0.62$ \\
\hline $\operatorname{IgE}(\mathrm{U} / \mathrm{L})$ & $299.49 \pm 444$ & $271.11 \pm 401$ & $679.9 \pm 893$ \\
\hline Correlation of eosinophils and IgE & $0.89 \mathrm{~b}$ & $0.81 \mathrm{c}$ & $-0.3 d$ \\
\hline
\end{tabular}

Eosinophils: eosinophil count in blood. Immunoglobulin E (IgE): total IgE in serum.

Pearson's correlation. $\mathrm{bp}=0.0001$. $\mathrm{cp}=0.01$. $\mathrm{dp}=0.21$. 
in Mexico corresponded to winter. ${ }^{10,12}$

A meta-analysis of predictive factors of early wheezing in childhood included male sex as an independent predictor of wheezing in children younger than 6-8 years with an odds ratio (OR) of 2.8 (95\% confidence interval [CI]: 1.08-7.28, $\mathrm{p}=0.034) .{ }^{13}$ In our population, no differences were observed in terms of sex: 91 girls $(43.1 \%)$ and 120 boys (56.9\%) were hospitalized. Kwon et al., reported a risk association among asthma exacerbation, male sex, and viral infection caused by rhinovirus or influenza. ${ }^{8}$

\section{Isolated viruses}

Twenty percent of children with asthma exacerbation hospitalized in the Emergency Department had a virus isolated in their nasopharyngeal secretion samples, as reported by Green et al., in 2002, A virus was isolated in only $17 \%$ of their population in a study on the synergy between aeroallergens and viruses as a risk factor for hospitalization due to asthma. ${ }^{14}$ This was very different from the hypothesis that respiratory infections were associated with 80$85 \%$ of asthma exacerbations in schoolchildren. ${ }^{15}$

The viruses most commonly associated with asthma exacerbation are rhinovirus, RSV, metapneumovirus, and influenza. ${ }^{5,11}$ In our study, the most commonly isolated virus was rhinovirus, found in $26.9 \%$ of asthma exacerbation cases. In 2015, Moreno et al, in a study conducted in Mexico, found that the most commonly isolated virus in children younger than 15 years with asthma exacerbation was rhinovirus. ${ }^{16}$ Kwon et al., in their study from 2014, reported that children with rhinovirus infection had a higher risk for asthma exacerbation. ${ }^{8}$

Enterovirus was isolated in $19.2 \%$ of cases with asthma exacerbation. In the bibliography, this virus was not commonly associated with asthma exacerbation. However, in 2015, Kato et al. reported the isolation of rhinovirus, RSV, and enterovirus in children younger than 3 years with asthma exacerbation. ${ }^{3}$ Also, in 2016 in Mexico, Vázquez et al, reported that rhinovirus was followed by enterovirus as the most commonly isolated virus in children younger than 15 years with respiratory infection. By the end of 2014, an enterovirus outbreak was reported in the United States, Canada, and the Netherlands in children who had asthma exacerbation, required mechanical ventilation, and developed weakness and spinal cord injury. ${ }^{12}$ Both in the study by Vázquez et al. and in our study, no neurological alterations were observed in the patients with asthma exacerbation who had enterovirus isolation.

Recent studies have focused on the interaction between enterovirus infection and other risk factors for asthma development. Children with repeated wheezing episodes caused by rhinovirus during childhood have a greater risk for developing asthma, even compared to those with wheezing caused by RSV. In asthma patients, viral infections cause an imbalance in the immune homeostasis of the respiratory system. They

FIGURE 1. Correlation between eosinophil levels in peripheral blood and total immunoglobulin E in serum in children with asthma exacerbation and isolation of viruses of the Picornaviridae family

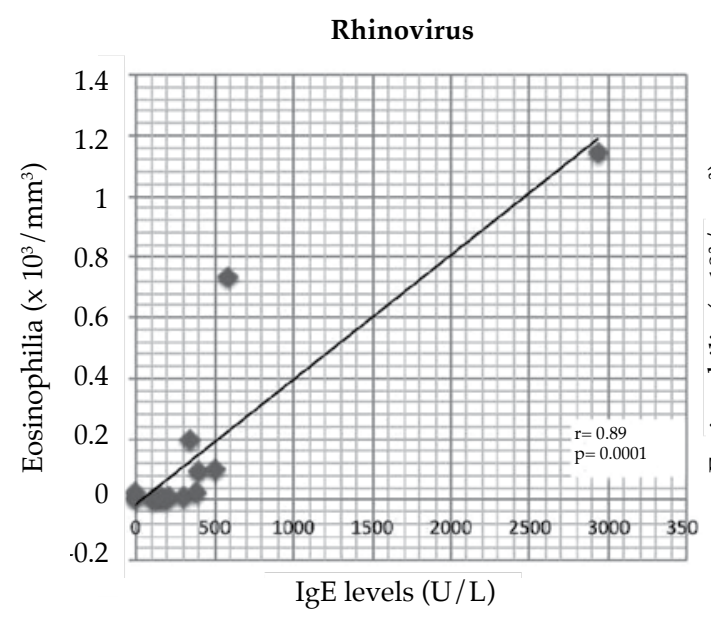

$\operatorname{IgE}$ levels $(\mathrm{U} / \mathrm{L})$

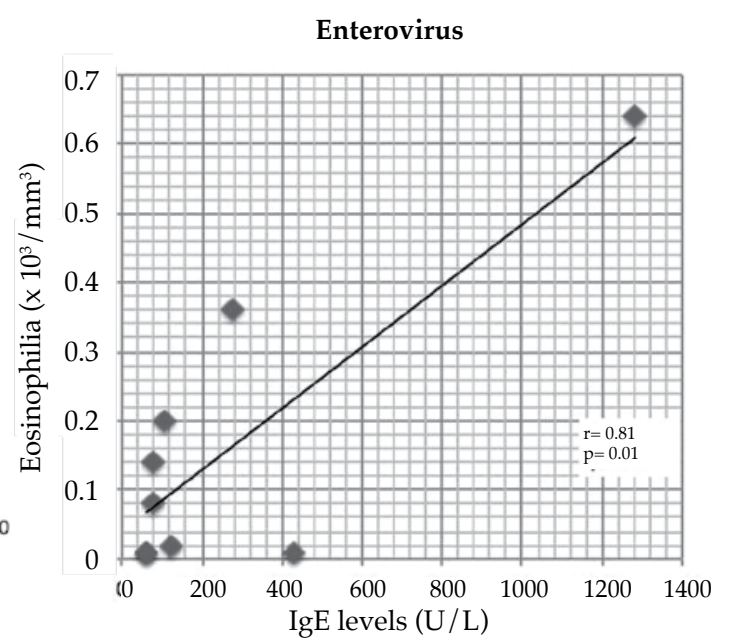


increase proinflammatory cytokines and cause the subsequent restructuring of the airways, such as smooth muscle enlargement, angiogenesis, goblet cell hyperplasia, and increased mucin production, related to hyperresponsiveness. ${ }^{17,18}$ Rhinovirus also increases interleukin 4 and Th2 cells related to allergic inflammation and reduced interferons as antiviral respose. ${ }^{7}$

\section{Eosinophils and total serum immunoglobulin E levels}

Eosinophils play a key role in the promotion and maintenance of airway inflammation, fibrosis, and angiogenesis. ${ }^{18}$ Eosinophil inflammation has been related to a greater risk for asthma exacerbation. ${ }^{7}$ A study in adults conducted in England in 2015 reported that patients with asthma and a blood eosinophil level $\geq 4 \times 103$ / $\mathrm{mm}^{3}$ had more severe exacerbations and a poorer asthma control. ${ }^{4}$ In a meta-analysis of predictive values for asthma exacerbation, eosinophilia in blood was considered a minor criterion, unlike eosinophilia in the nasopharyngeal aspirate, which accounted for an independent risk factor for persistent asthma during childhood. ${ }^{13}$ In our study, the eosinophil level was not very high; however, it was found to be higher among children with rhinovirus isolation compared to the other viruses. Likewise, Vázquez et al., in a study conducted in Mexico in 2016, did not find eosinophilia in patients with respiratory infections caused by rhinovirus and enterovirus; and Kwon et al, only established that eosinophils were higher among asthmatic children compared to those with bronchiolitis and pneumonia, although it was not statistically significant. ${ }^{8,12}$ A much larger sample is probably required to observe the association between eosinophilia and asthma exacerbation in pediatric patients, as reported in adults.

A history of rhinitis, atopic dermatitis or atopy was not found to be more frequent in children with asthma exacerbation and an isolated virus; besides, a relationship between total serum IgE levels and the most commonly isolated viruses, such as rhinovirus and enterovirus, was not observed. However, when establishing a correlation between blood eosinophil levels and total serum IgE levels, a positive correlation was found in children with asthma exacerbation and rhinovirus $(p=0.0001)$, and enterovirus $(p=0.01)$, unlike with other viruses $(\mathrm{p}=0.21)$. IgE shows a high affinity for plasmacytoid dendritic cells and inhibits the cells' ability to produce interferons with a poor response to viral infection. ${ }^{7}$ Kato et al. reported a correlation between chemokine 10 and age, but not between eosinophilia and age. ${ }^{3}$ Kown et al. also observed that total serum IgE was higher among children with asthma exacerbation than with other respiratory infections without a statistical association with some other virus. ${ }^{8}$ However, neither Kato nor Kown established a correlation with these two outcome measures in the presence of a virus, as in this study.

Eosinophilia and total serum $\operatorname{IgE}$ are predictors of asthma because they are related to allergen factors. Establishing a correlation between these two factors in the presence of an isolated virus supports the theory that viruses and allergens are triggers of asthma.

The limitations of this study were its small sample size, that it only included children who were ill enough to require hospitalization without a comparison to stable asthma children, that eosinophilia and serum IgE in children with and without a positive viral panel were not compared, and that eosinophils in sputum and specific IgE were not measured. However, although this is only a correlation study, our observations encourage the conduct of more detailed studies regarding these outcome measures.

To conclude, rhinovirus, enterovirus, and RSV are the most commonly isolated viruses in children younger than 15 years with asthma exacerbations. Multiple predictive values, such as a history of allergens, eosinophilia (blood and nasopharyngeal secretion). IgE levels (total or specific), and specific virus infections are associated with asthma exacerbation, but genetics may not be modified and there are no effective antivirals available at this time, so strategies aimed at reducing hospitalizations in children with asthma exacerbation should focus on prevention. Further studies are required to understand the relationship between viruses, allergens, and inflammatory processes.

\section{REFERENCES}

1. Plaza Moral V, Álvarez Rodríguez C, Gómez Outes A, et al. GEMA4.0. Guía española para el manejo del asma. Madrid: Luzán5; 2015. [Accessed on: April 15th. 2017]. Available at: http: / www.gemasma.com.

2. Beydon N, Cochez M, Mahut B, et al. Acoidable emergency visit for acute asthma in children: Prevalence and risk factors. Pediatr Allergy Immunol Pulmonol 2016;29(3);130-6.

3. Kato M, Suzuki K, Yamada Y, et al. Virus detection and cytokine profile in relation to age among acute exacerbations of childhood asthma. Allergol Int 2015;64 Suppl:S64-70.

4. Price DB, Rigazio A, Campbell JD, et al. Blood eosinophil 
count and prospective annual asthma disease burden: a UK cohort study. Lancet Respir Med 2015;3(11):849-58.

5. Costa LD, Costa PS, Camargos PA. Exacerbation of asthma and airway infection: is the virus the villain?. J Pediatr (Rio J) 2014;90(6):542-55.

6. Jackson DJ, Evans MD, Gangnon RE, et al. Evidence for a causal relationship between allergic sensitization and rhinovirus wheezing in early life. Am J Respir Crit Care Med 2012;185(3):281-5.

7. Kim WK, Gern JE, Updates in the relationship between human rhinovirus and asthma. Allergy Asthma Immunol Res 2012;4(3):116-21.

8. KwonJM, Shim JW, Kim DS, et al. Prevalence of respiratory viral infection in children hospitalized for acute lower respiratory tract diseases. and association of rhinovirus and influenza virus with asthma exacerbations. Korean J Pediatr 2014;57(1):29-34.

9. Baeza Bacab M, Barrera Cruz A, Becerril Ángeles M, et al. Diagnóstico y manejo del asma en menores de 18 años de edad en el primer y segundo nivel de atención. México: Secretaría de Salud; 2013. [Accessed on: October 13th. 2017]. Available at: http:/ / www.cenetec-difusion.com/ CMGPC/S-009-08/ER.pdf.

10. Barraza-Villarreal A, Sanín-Aguirre LH, Téllez-Rojo MM, et al. Prevalencia de asma y otras enfermedades alérgicas en niños escolares de Ciudad Juárez, Chihuahua. Salud Pública Méx 2001;43(5):433-43.

11. Inoue $\mathrm{Y}$, Shimojo N, Epidemiology of virus-induced wheezing/asthma in children. Front Microbiol 2013;4:391.

12. Vázquez-Pérez J, Ramírez-González J, Moreno-Valencia Y, et al.EV-D68 infection in children with asthma exacerbation and pneumonia in Mexico City during 2014 autumn. Influenza Others Respir Viruses 2016;10(3):154-60.

13. Rodríguez-Martínez CE, Sossa-Briceño MP, CastroRodriguez JA. Factors predicting persistence of early wheezing through childhood and adolescence: a systematic review of the literature. J Asthma Allergy 2017;10:83-98.

14. Green RM, Custovic A, Sanderson G, et al. Synergism between allergens and viruses and risk of hospital admission with asthma: case-control study. BMJ 2002;324(7340):763.

15. Johnston SL, Pattemore PK, Sanderson G, et al. Community study of role of viral infections in exacerbations of asthma in 9-11 years old children. BMJ 1995;310(6989):1225-9.

16. Moreno-Valencia Y, Hernández-Hernández V, RomeroEspinoza J, et al. Detection and characterization of respiratory viruses causing acute respiratory illness and asthma exacerbation in children during three different seasons (2011-2014) in Mexico City. Influenza Other Respir Viruses 2015;9(6):287-92.

17. Proud D. Role of rhinovirus infections in asthma. Asian Pac J Allergy Immunol 2011;29(3):201-8.

18. Castro M, Zangrilli J, Wechsler M, et al. Reslizumab for inadequately controlled asthma with elevate blood eosinophil counts: result from two multicentre. parallel. doble-blind.randomised. placebo-controlled. phase 3 trials. Lancet Respir Med 2015;3(5):355-66. 